Luciana Pereira

Silva

Universidade Federal de

Pernambuco - Recife, PE.

Brasil.

Isaltina Maria de

Azevedo Mello

Gomes

Universidade Federal de

Pernambuco - Recife, PE.

Brasil.

\section{Ideologia, jornalismo e meio ambiente}

\author{
Ideology, journalism \\ and the environment
}

Ideología, periodismo y medio ambiente 


\section{RESUMO}

O Complexo Industrial Portuário de Suape (CIPS) foi projetado na década de 1970 e teve seu funcionamento inicial em 1986, traçado com o objetivo primeiro de administrar as obras de implantação do Porto de Suape em substituição ao Porto do Recife. No ano de 2007, o CIPS esteve presente nas páginas dos jornais de Pernambuco como "o maior gerador de emprego e renda". É possível que tenham sido celebrados acordos e investimentos financeiros entre o governo de Pernambuco e os grupos gestores e parceiros para a instalação de empreendimentos tanto na área do Complexo como no seu entorno. Por outro lado, percebe-se que, tanto para a instalação, como para o funcionamento dos empreendimentos, houve vários impactos no meio ambiente. No entanto, no período estudado, há a ausência de discussão, na mídia impressa, sobre os impactos ambientais gerados pelo Complexo na área de sua instalação e no seu entorno. Neste artigo, serão discutidas como as questões ideológicas imbricadas no discurso da imprensa podem valorizar os aspectos econômicos em detrimento dos aspectos ambientais. O corpus selecionado para análise é composto por três notícias publicadas nos jornais de Pernambuco: Diario de Pernambuco, Folha de Pernambuco e Jornal do Commercio, escolhidas de forma aleatória. A análise deixa entrever como o discurso da imprensa pode silenciar determinados aspectos em detrimento de outros, particularmente, quando se leva em consideração o poder e a ideologia que permeiam a prática social e discursiva.

Palavras-chave: Ideologia. Jornalismo. Meio-ambiente. Complexo Industrial Portuário de Suape (CIPS)

\section{ABSTRACT}

The Industrial Port Complex of Suape [Complexo Industrial Portuário de Suape (CIPS)] became a project in the 1970s and began functioning in 1986, having as its first objective to administrate works to implant the Port of Suape, substituting the Port of Recife. In 2007 the Complex became known in Pernambuco's press as "the greatest source of employment and wealth". It has been possible to celebrate financial agreements and investments between the government of Pernambuco, management groups and partnerships for the installation of enterprises in the area of the Complex and, equally, in the surrounding areas. On the other hand, one perceives that just as much in the installation as in the functioning of enterprises, there were a variety of impacts on the environment. However, in the period under study there is an absence of discussion, in the print media, about the environmental impacts generated by the Complex within the area of its installation and in surrounding areas. In this article it will be discussed how ideological questions embedded in the press's discourse can come to value economic aspects to the detriment of environmental aspects. The corpus selected for analysis is composed of three sets of news published in Pernambuco's newspapers: Diario de Pernambuco, Folha de Pernambuco and Jornal do Commercio, selected at random. The analysis allows one to observe how the press's discourse can silence certain aspects to the detriment of others, particularly when one takes into consideration the power and ideology which permeate social and discursive practices.

Key-words: Ideología, periodismo y medio ambiente

\section{RESUMEN}

El Complexo Industrial Portuário de Suape (CIPS) fue proyectado en la década de 70 del siglo XX y tuvo su funcionamiento inicial en 1986, teniendo como primer objetivo administrar las obras de implantación del Puerto de Suape en sustitución al Puerto de Recife. El año de 2007 el CIPS estuvo presente en las páginas de periódicos de Pernambuco como "el mayor generador de empleo y renta". Es posible que hayan sido celebrados acuerdos e inversiones financieras entre el gobierno de Pernambuco con gerentes y socios para la instalación de emprendimientos tanto en el área del CIPS como en su entorno. Por otro lado, se percibe que tanto para la instalación como para el funcionamiento de los emprendimientos hubo varios impactos al medio ambiente. Sin embargo, en el período estudiado hay la ausencia de discusión, en los periódicos, de los impactos ambientales generados por el CIPS en el área de su instalación y en su rededor. En este artículo serán discutidas cómo las cuestiones ideológicas aplicadas en el discurso de la prensa pueden valorar los aspectos económicos en detrimento de los aspectos ambientales. El corpus seleccionado para análisis es compuesto por tres noticias publicadas en los periódicos de Pernambuco: Diario de Pernambuco, Folha de Pernambuco y Jornal do Commercio, elegidas de modo aleatorio. El análisis deja percibir como el discurso de la prensa puede silenciar determinados aspectos en detrimento de otros, particularmente, cuando se lleva en consideración el poder y la ideología que impregnan la práctica social y discursiva.

Palabras clave: deología. Periodismo. Medio ambiente. Complexo Industrial Portuário de Suape (CIPS).

Submissão: $11-8-2017$

Decisão editorial: 25-6-2020 


\section{Introdução}

O presente artigo tem como proposta analisar como a ideologia no discurso da imprensa pode contribuir para uma determinada concepção de realidade. Nosso interesse é verificar nas notícias impressas dos jornais locais (Diario de Pernambuco, Jornal do Commercio e Folha de Pernambuco) se os impactos ambientais atribuídos ao Complexo Industrial Portuário de Suape (CIPS) são discutidos nesses veículos.

Projetado há cerca de quarenta anos, com o intuito inicial de administrar as obras de implantação do Porto de Suape para substituir o Porto do Recife, o CIPS teve seu funcionamento inicial em 1986. Sua área é constituída, entre outros, por instalações portuárias terrestres, abrangendo cais, docas, pontes e píeres de atracação e de acostagem, vias de circulação interna e terrenos pertencentes à União, sendo parte deles incorporados ao patrimônio do porto. Sua concepção origina-se no moderno conceito de integração porto-indústria (ALVES, 2011).

Compreende-se que a construção do CIPS gerou impactos significativos para o entorno como também para a população local dos municípios de Cabo e Ipojuca, a saber: a crescente demanda por moradia por parte de trabalhadores que buscaram residir próximo ao trabalho, a diversificação das atividades 
de comércio e serviços, a requalificação de casas de segunda em primeira residência, o aumento do tráfego urbano, o aumento da produção de resíduos sólidos, o aumento no consumo de água, a migração de trabalhadores de outros estados, o aumento da prostituição e o consequente aumento da violência urbana. Todos esses fatores citados podem, possivelmente, contribuir de forma significativa para intensificar os impactos ambientais.

Sabemos que as questões ambientais têm gerado preocupação e consequente intensificação de debates e exposição da temática na mídia. A comunicação ambiental torna-se um veículo pragmático e constitutivo que funciona para a concepção de meio ambiente e para a percepção das relações das pessoas com a natureza, alem de ser pragmática, porque educa, adverte, persuade, mobiliza e age para o debate público sobre o meio ambiente e é constitutiva, por possibilitar a construção das imagens sobre o meio ambiente, sendo um elo para a sua propagação (COX, 2010).

Discutiremos aqui como o discurso noticioso pode silenciar conteúdos em detrimento de outros, assim como pode apontar uma possível (re)significação de alguns aspectos do mundo social. E, por fim, apresentaremos a perspectiva ideológica imbricada no discurso noticioso, levando em consideração a prática social e discursiva.

\section{Comunicação ambiental e ideologia}

\subsection{Comunicação ambiental}

A comunicação ambiental é uma atividade humana que pode auxiliar na compreensão das ques- 
tões e problemas ambientais, ajudar na recuperação ambiental causada pela ação do homem na natureza, bem como educar e promover a relação harmoniosa do homem com o meio ambiente. Por isso, torna-se imprescindível compreender as práticas sociais e discursivas que envolvem questões ambientais.

Para Cox (2010, p.14-18), enquanto campo de estudo, a comunicação ambiental apresenta sete áreas de atuação:

a) retórica ambiental e construção social simbólica da natureza: observa como a linguagem ajuda na compreensão e construção ou representação da natureza, ou seja, a linguagem como forma simbólica de ação contribuindo para a formação de imagens e representações da natureza;

b) participação pública nas decisões ambientais: estuda como a participação pública nas demandas e questões ambientais podem auxiliar numa forma mais dinâmica de pensar essas questões, uma vez que melhoram a qualidade das informações e legitimam as decisões.

c) colaboração e resolução dos conflitos: propõe-se a estudar a colaboração como princípio norteador para a resolução dos conflitos ambientais e abrange desde os comentários dos cidadãos sobre o manejo florestal ao acesso das pessoas às informações ambientais;

d) mídia e jornalismo ambiental: discute como as notícias, a publicidade, os programas, assim como os conceitos norteadores do jornalismo - tais como agenda-setting, objetividade, enquadramento - e as novas mídias influenciam 
na construção, na formação e na produção de sentido sobre as questões e os problemas ambientais;

e) representações da natureza na publicidade corporativa e da cultura popular: discute como as imagens da natureza no cinema, na fotografia, na televisão e na música influenciam a atitude das pessoas sobre o meio ambiente e a natureza;

f) campanhas de defesa e construção de mensagens: trata-se do uso da educação pública, das campanhas de defesa de grupos ambientais e do marketing.

As áreas de atuação da comunicação ambiental podem ser trabalhadas na perspectiva de possibilitar um olhar crítico sobre as questões do meio ambiente, particularmente, por se tratar de uma área pragmática e constitutiva. Assim, a comunicação ambiental tanto orienta e mobiliza para o debate público como auxilia na formação do cidadão sobre os problemas e questões ambientais.

Cox (2010) considera que a comunicação humana é uma forma simbólica de ação e as crenças, as atitudes e os comportamentos em relação ao meio ambiente são mediados e influenciados pela comunicação. Corbet† (2006) afirma que os sistemas de crenças são produtos individual e cultural, ao mesmo tempo em que as mensagens são criadas a partir de uma concepção de mundo, referindo-se às relações e experiências pessoais para justificar palavras e ações. Nesse sentido, a autora argumenta que as crenças, as orientações e as visões de mundo são criadas a partir de perspectivas ideológicas, tornando-se o re- 
ferencial para a interpretação de palavras, ações e comportamentos. Dessa forma, cria-se uma ideologia ambiental, ou seja, trata-se de "uma maneira de pensamento sobre o mundo natural que as pessoas usam para justificar suas ações sobre ele" (CORBETT, 2006, p. 26).

A compreensão da autora tem o mesmo princípio adotado por Bakhtin (2004, p 37, grifos do autor) quando afirma: "[...] existe uma parte muito importante da comunicação ideológica que não pode ser vinculada a uma esfera ideológica particular: trata-se da comunicação na vida cotidiana".

Desse modo, pensar a comunicação, os problemas e as questões ambientais dissociados da discussão de como a palavra, como fenômeno social e ideológico, pode ser utilizada para silenciar determinados conteúdos em detrimento de outros chega a ser contraditório. Afinal já afirmava Bakhtin (2004) que não pronunciamos palavras, mas coisas boas ou ruins com teor agradável ou desagradável, considerando a palavra como indicador para interpretação dos atos ideológicos. "Todas as manifestações da criação ideológica - todos os signos não verbais - banham-se no discurso e não podem ser totalmente isoladas nem totalmente separadas dele" (BAKHTIN, p.38).

pensamento do autor, contextualizado com a discussão proposta neste trabalho, leva-nos a inferir que as escolhas das palavras podem carregar conteúdos ideológicos, conduzindo as pessoas à aceitação ou não de determinadas informações, ou seja, promovendo juízos de valor.

A compreensão de Bakhtin tem o mesmo princípio adotado por Dryzek (2013, p. 12) quando comenta: "discursos são importantes, e condicionam a 
maneira que nós definimos, interpretamos e tratamos as questões ambientais". Para Dryzek um discurso é um modo de compartilhar e apreender o mundo, construindo significados, apresentando julgamentos e contestações.

$\mathrm{E}$, retomando o discurso sobre as questões e os problemas ambientais, Dryzek (2013) pontua que os discursos podem estar imbricados de práticas de poder e condicionar a percepção e os valores das pessoas sujeitas a eles, difundindo determinados interesses e suprimindo outros. Esse pensamento é reforçado pela afirmação de que é pela linguagem que se constrói e se interpreta as questões ambientais.

Percebe-se, portanto, que as relações de poder e dominação podem vir acentuadas, mascaradas ou ofuscadas por determinadas escolhas. Assim, compreender as nuances do discurso e como as ideologias podem estar impregnadas no tecido social permite um olhar sobre a prática discursiva e social da sociedade.

\subsection{Ideologia}

A concepção de ideologia de Thompson (2009) fundamenta-se na concepção latente de Marx, porém, mantém de forma modificada o critério da negatividade, como característica norteadora da ideologia, ou seja, sustentação das relações de dominação. Outro ponto a ser considerado, mas com alterações, é o critério de dominação que, na obra de Marx, está condicionada às relações de classe, e para Thompson a dominação é mantida pelo sentido, mas serão observados outros tipos de dominação, a saber: as relações sociais entre homens e mulheres, 
entre grupos étnicos, entre estados-nação hegemônicos e outros estados-nação localizados à margem do sistema global.

Na concepção de sua teoria crítica da ideologia, três aspectos foram requeridos. São eles: a noção de sentido, o conceito de dominação e as maneiras como o sentido pode ser utilizado para estabelecer e sustentar as relações de dominação. E esse sentido é o presente nas formas simbólicas inseridas nos contextos sociais e circulando no mundo social (THOMPSON, 2009).

Por "formas simbólicas" eu entendo um amplo espectro de ações e falas, imagens e textos, que são produzidos por sujeitos e reconhecidos por eles e outros como construtos significativos. Falas linguísticas e expressões, sejam elas faladas ou escritas, são cruciais a esse respeito, mas formas simbólicas podem também ser não linguísticas em sua natureza (por exemplo, uma imagem visual ou um construto que combina imagens e palavras) (THOMPSON, 2009, p. 79, grifos do autor).

O autor esclarece que as formas simbólicas devem ser analisadas, levando em consideração os seguintes aspectos: "intencional", "convencional", "estrutural" e "referencial", acrescentando o aspecto "contextual", ou seja, as formas simbólicas estão sempre inseridas em um contexto. Logo, essas características apresentadas tanto para sentido quanto para a dominação são o pano de fundo para a apresentação da proposta do autor.

O modelo proposto por Thompson (2009, p. 80-89) distingue cinco modos de operação da ideologia. São eles: a) legitimação; b) dissimulação; c) unificação; d) fragmentação e; e) reificação. 
No processo de legitimação, as relações de dominação podem ser instituídas como legítimas, utilizando as estratégias da racionalização, da universalização ou da narrativização.

Já o segundo modo de operação da ideologia é a dissimulação. Nesse caso as relações de dominação podem ser instituídas e amparadas, uma vez que são escondidas, negadas ou ofuscadas, por serem representadas de forma que desviam a atenção. Esse processo pode ser expresso pelo descolamento quando um termo é utilizado para se referir a outro, com conotações positivas ou negativas. Pode, ainda, ser expresso pela eufemização quando determinadas ações são valorizadas. Outro processo é o tropo, emprego figurativo da linguagem, podendo mascarar relações de dominação.

Na unificação, as relações de dominação são sustentadas através da construção de uma identidade coletiva, independe das diferenças e divisões que podem separar os indivíduos. Nesse processo, utiliza-se a estratégia da padronização na qual as formas simbólicas são adaptadas a um indicador padrão e a uma simbolização da unidade.

Na fragmentação, sua forma de hegemonia acontece por meio da diferenciação, ou expurgo do outro quando distinções são feitas de modo a apoiar características que possam afastar grupos ou indivíduos, instituindo-se um repto efetivo nas suas relações de convivência.

Por fim, no processo de reificação, as relações de poder e de dominação são instituídas como históricas, ou seja, as situações são concebidas como permanentes, naturais, atemporais, sendo os processos tratados como "comuns" e "coisificados", utiliza as 
estratégias como: a naturalização, a eternalização e nominalização/passivização (THOMPSON, 2009).

\section{0 discurso da imprensa escrita e as questões ambientais}

De acordo com Dryzec (2013), o discurso pode ser considerado uma maneira compartilhada de apreender o mundo permeado pela linguagem. A partir dele, são construídas representações e oferecem-se julgamentos de valor, possibilitando a definição de senso comum e legitimando conhecimento. O autor orienta que os discursos estão ligados às práticas de poder, condicionando a percepção e os valores das pessoas, conduzindo ao fortalecimento ou a omissão de interesses.

Segundo o autor, o discurso sobre as questões ambientais surgiu na sociedade industrial e deve ser estudado contextualizado com o discurso da industrialização. Nesse caso, esses discursos são caracterizados como aqueles envolvidos com o crescimento global na produção de bens e serviços e para o bem-estar material que podem ser oferecidos nas sociedades industriais. Portanto, são permeados por distintas perspectivas ideológicas, porém havendo o comprometimento com a industrialização.

Consequentemente, identificar os jornais como um espaço para difundir as questões e os problemas ambientais e pensar a comunicação ambiental como aquela que permite aos cidadãos o acesso à informação, promovendo desde a socialização da informação ao engajamento para a melhoria das condições de vida e preservação do meio ambiente pode ser desafiador e contraditório. Na perspectiva do desafio, trata-se de identificar como no jornalis- 
mo impresso as questões ambientais estão sendo discutidas; e contraditório, uma vez que a informação está concentrada nas mãos de poucos grupos corporativos.

Isso pode ser corroborado pelo entendimento de Santos (2010, p.32):

A informação é centralizada nas mãos de um número extremamente limitado de firmas. Hoje, o essencial do que no mundo se lê, tanto em jornais como em livros, é produzido a partir de meia dúzia de empresas que, na realidade, não transmitem novidades, mas as reescrevem de maneira específica.

Santos adverte, ainda, que a informação concentrada nas mãos de grupos pequenos tende a refletir os interesses corporativos e acrescenta: "Essas técnicas de informação (por enquanto) são apropriadas por alguns Estados e por algumas empresas, aprofundando assim os processos de criação de desigualdades" (SANTOS, 2010, p. 20, grifo do autor).

Para o autor, a periferia do capitalismo se torna mais periférica. Compreende-se que esse distanciamento seja atribuído pelo pouco acesso que os cidadãos têm à informação para o exercício de sua cidadania. Santos (2010, p. 20) resume: "o que é transmitido à maioria da humanidade é, de fato, uma informação manipulada que, em lugar de esclarecer, confunde".

As palavras de Santos são ratificadas no dia a dia da nossa imprensa, pois o que observamos é que a informação ambiental ou é transmitida de forma alarmista ou transfere ao cidadão a "responsabilidade" por demandas que ele não tem a competência de gerenciar. 
Nessa perspectiva Hall et al (2016, p. 323, grifos nossos) afirmam:

Em sociedades onde o grosso modo da população não tem acesso direto nem poder sobre as decisões centrais que afetam as suas vidas, onde a política oficial e opinião estão concentradas e a opinião popular está dispersa, os media desempenham um papel de ligação e de mediação crítica na formação da opinião pública e na orquestração dessa opinião com as ações e perspectivas dos poderosos.

Para pontuar o acesso do cidadão à informação, trazemos a seguir alguns dados da Pesquisa Brasileira de Mídia - PBM (2015). Ressalte-se, no entanto, que neste artigo apenas as questões relacionadas ao jornal impresso serão discutidas. Segundo o estudo, o baixo índice de leitura dos jornais impressos não deve incidir sobre sua importância enquanto veículo de informação, mas deve-se levar em consideração que as características sociodemográficas afetam os resultados da pesquisa, dentre elas: escolaridade, renda etc.

A PBM (2015) aponta que o consumo de jornal impresso apresenta as seguintes informações: quanto à leitura do jornal no formato impresso, $76 \%$ dos entrevistados afirmaram não ler jornal; $21 \%$ leem uma vez por semana; e apenas $7 \%$ leem todos os dias; porém os que leem preferem o formato impresso, $79 \%$ dos leitores; os motivos que levam os leitores ao jornalismo impresso continua sendo a busca por informação, $84 \%$. A pesquisa informa, ainda, que, dentre os respondentes da pesquisa, apenas $13 \%$ são assinantes do jornal e as formas de acesso à leitura podem ser desde comprando na banca, 58\%, lendo de outras pessoas/biblioteca/consultório/local de trabalho, $20 \%$. 
É preciso levar em consideração que a pesquisa apresenta que no estado de Pernambuco, onde existem três grandes jornais: Diario de Pernambuco, Folha de Pernambuco e Jornal do Commercio, $74 \%$ da população não lê jornal. Também é possível verificar que a leitura do jornal impresso está mais presente entre as pessoas com maior escolaridade e poder aquisitivo, ou seja, dentre aqueles com renda maior que cinco salários mínimos, $15 \%$ leem o jornal todos os dias e o percentual com curso superior corresponde a $9 \%$ dos que buscam informação com a mesma frequência, além de que o uso das plataformas digitais para leitura de jornais é baixo.

É curioso observar que, segundo a PBM (2015), apenas $2 \%$ dos entrevistados buscam informação sobre o meio ambiente nos jornais impressos. Vale ressaltar que, no caso dos jornais, objeto de estudo deste artigo, apenas o Jornal do Commercio possuía uma editoria de ciência e meio ambiente. Nos demais, as discussões sobre questões e problemas ambientais estavam distribuídas ao longo do jornal.

A nosso ver, alguns fatores podem favorecer o pouco interesse do público pela temática ambiental. Dentre eles citamos: a falta de informação sobre a temática, o tipo de informação (alarmista), a pouca escolaridade. Marques Filho $(2016$, p. 27) ratifica nossa afirmação:

O que dizer, entretanto, da quase indiferença da grande maioria mais imediatamente vulnerável à crise planetária dos ecossistemas? A marginalização (política, econômica, educacional etc.) e a luta esfalfante explicam essa quase indiferença. Mas não se subestime o poder explicativo de outro fator: as promessas da sociedade de consumo. 


\section{Uma breve análise}

Neste artigo, as notícias, objeto de análise, foram publicadas no primeiro semestre de 2007 e foram selecionadas utilizando a metodologia da semana construída, uma abordagem na qual se constrói uma semana de forma aleatória, possibilitando que todos os dias da semana sejam contemplados (RIFFE; AUST; LACY, 1993). No período de janeiro de 2007 a junho de 2007, montamos uma semana, a fim de realizar uma pesquisa exploratória da temática do meio ambiente nas páginas dos jornais de Pernambuco em associação com o período de grandes investimentos financeiros com as obras no entorno do Complexo Industrial Portuário de Suape (CIPS).

Para a discussão, selecionamos, de forma aleatória, dentre as notícias encontradas no período, uma de cada jornal, a saber: Diario de Pernambuco [PE deve ganhar siderúrgica de US\$150 milhões (N1) 10/ fev./2007]; Folha de Pernambuco [Governo destinará verbas para acesso em Suape, 1\%/fev. 2007, (N2)]; Jornal do Commercio [Estaleiro: obra começa em uma semana, 1\% fev/2007, (N3)].

Dentre as notícias coletadas no período, não havia em nenhuma a proposição ou discussão dos impactos ao meio ambiente que poderiam advir com as obras no entorno do Complexo Industrial Portuário de Suape (CIPS). Na (N3), havia a informação de que: "a terraplanagem da obra começa na próxima semana e, em 45 dias, terá início a implantação das estacas na llha de Tatuoca, em Suape, onde ficará localizado o empreendimento" (LIMA, 2007, p.1). Já na (N2), informa-se a "terraplanagem de 620 hectares destinada à planta no complexo portuário" (CRISTO, 2007, p. 3). Muito embora as notícias apresentassem 
a informação da terraplanagem na ilha e no entorno do CIPS, não houve discussão sobre as questões ambientais. É importante destacar que os enunciados apresentados nas notícias reforçam a prática discursiva do progresso, ou seja, "o Estado como um canteiro de obras".

Diante das discussões apresentadas nas notícias e da constante alusão ao crescimento econômico, encontramos respaldo em Marques Filho (2016, p. 28, grifo do autor): "Esse consenso de que o crescimento econômico contínuo é uma condição de possibilidade de uma sociedade segura e próspera é obviamente funcional às corporações e a seu espectro político 'clássico'".

Nas notícias (N1), (N2) e (N3), há uma associação do CIPS com a geração de emprego e renda: É o caso dos enunciados: "está prevista a geração de 220 empregos diretos e 550 indiretos" (DP, 2007); "na construção do estaleiro, serão geradas 2000 vagas, sendo 5000 diretas quando ele estiver operando. 0 número de empregos indiretos pode chegar a 20.000" (LIMA, 2007, p.1).

Para Bakhtin (2004), a palavra enunciada constitui-se como produto ideológico. Assim, ao enunciar a geração de empregos e renda, pronunciam-se palavras agradáveis e reforçar-se a ideologia do crescimento econômico.

Nessa mesma perspectiva, identificamos que no título da (N1) - "PE deve ganhar siderúrgica de US\$ 150 milhões", a palavra "ganhar" indica algo como "Uma dádiva" para o estado. No entanto, compreendemos que, para se instalar no estado, é possível que vários acordos entre o governo estadual e o grupo 
corporativo que tem os direitos sobre a siderúrgica tenham sido firmados.

Marques Filho (2016, p. 37) explica a relação de aproximação entre o Estado e as corporações, afirmando:

[...] hoje, a tal ponto os Estados amalgamam-se física, política e financeiramente com as corporações que começam a se borrar os limites entre eles, de modo que se torna por vezes impossível precisar onde termina o Estado e onde começa o grande capital corporativo.

O Índice de Desenvolvimento Humano Municipal - IDHM', ano de 2000, dos municípios do Cabo de Santo Agostinho e Ipojuca apresentaram os seguintes dados: a) Cabo de Santo Agostinho, IDHM, 0,547; renda, 0566; longevidade, 0,734; educação, 0394. O município de Ipojuca, IDHM, 0457; renda, 0523; longevidade, 0712; educação, 0256. O IDHM dos municípios, portanto, não reflete o "crescimento e desenvolvimento" alardeado no período no discurso da imprensa.

No caso do Complexo Industrial Portuário de Suape (CIPS), pode-se sugerir que os impactos ambientais atribuídos ao empreendimento foram ofuscados ou dissimulados pela circulação de um discurso de supervalorização econômica. A questão é de cunho ideológico, uma vez que é possível compreender que um dos modos de operação da ideologia está presente, a dissimulação, quando determinadas situações são ofuscadas, negadas, utilizando as estratégias do

\footnotetext{
1 O Índice de Desenvolvimento Humano Municipal - IDHM é uma metodologia utilizada para avaliar o desenvolvimento humano, abrangendo três dimensões: longevidade, educação e renda. O índice varia de 0 a 1 , quanto mais próximo de 1 , maior 0 desenvolvimento.
} 
deslocamento, da eufemização e do tropo (THOMPSON, 2009).

O CIPS foi idealizado como um grande gerador de emprego e renda oriunda do setor industrial, uma vez que sinaliza que houve mudanças no perfil de investimento metropolitano (GARCIA; MUSSALEM, 2011). Para Garcia e Mussalem (2011), existe um Pernambuco antes de Suape e outro após a implantação e funcionamento do Complexo, em virtude do aporte elevado de recursos de investimentos industriais e logísticos na área do litoral sul. Porém, como afirmam Hall et al (2016, p.61), "a força do capitalismo reside no fato de projetar nas consciências uma imagem invertida de si, de modo que a desordem que produz surge como ordem natural das coisas".

Diante disso, perguntamos: seria possível o discurso ambiental prevalecer diante dos acordos firmados com grupos corporativos? De acordo com Marques filho (2016, p. 38, grifos do autor):

[...] apenas secundariamente, as pressões da sociedade civil para que o Estado reassuma sua identidade histórica de promotor de políticas ambientais e de bem-estar social. Apenas secundariamente, porque a capacidade e a disponibilidade dos Estados para atender a essas pressões são cada vez mais condicionadas pelo pacto corporativo que rege essa nova natureza emergente do Estado.

Compreendemos que existe a hegemonia do discurso econômico sobre o ambiental, particularmente, quando é possível perceber que questões ideológicas e políticas ofuscam os impactos ao meio ambiente e exalta-se o "crescimento econômico" e a "geração de emprego e renda". Não se discute o fato de que 
os empregos gerados são temporários nem que, após a conclusão das obras, haverá o desemprego.

Neste ponto, é importante trazer Hall et al (2016, p. 325), que discute como os media podem (re)produzir discursos que estão dentro do paradigma dominante:

Assim, os media ajudam a reproduzir e a manter as definições da situação que favorecem os poderosos, não só recrutando ativamente os poderosos nas etapas iniciais onde os tópicos são estruturados (Hall, 1975), mas favorecendo certas formas de expor tópicos e mantendo certas áreas estratégicas em silêncio.

Acreditamos que esse discurso econômico presente nas páginas dos jornais de Pernambuco sinalizando o crescimento econômico advindo com o CIPS seja uma relação de dominação que pode ser estruturada e sustentada por interligar os indivíduos numa identidade coletiva. Enunciados como "Pernambuco cresceu mais que o Brasil" podem ser considerados como de natureza ideológica, utilizando o modus operandi da unificação (THOMPSON, 2009).

Já em relação aos impactos ambientais que, possivelmente, foram causados, é possível constatar que existe silêncio ou dissimulação, identificando que o silêncio é também de natureza ideológica.

\section{Considerações finais}

Na sociedade em que vivemos, na qual a lógica do capitalismo impera, discutir os impactos causados por grandes empreendimentos ao meio ambiente pode ser considerado apenas mais uma visão utópica, particularmente, quando se faz de forma dissimulada a associação entre o "crescimento econômico" e o "desenvolvimento social". 
As relações que permeiam as práticas discursivas nem sempre são pautadas no interesse da coletividade e, se esses grupos sociais ou minorias podem vir a contrariar os interesses dominantes, silenciadas podem ser suas vozes, o que reflete a orientação para o modus operandi da ideologia corroborando com a literatura discutida no texto.

Compreender as mídias, particularmente, o jornal impresso como uma "esfera pública" para discussão da temática do meio ambiente e, no caso, dos impactos gerados por grandes empreendimentos, deixa-nos a possibilidade de refletir sobre a responsabilidade de buscar como essas informações foram noticiadas $e$, se realmente foram objeto de pauta do jornalismo impresso de Pernambuco, uma vez que, no período, a temática foi objeto de notícias em datas pontuais, ou seja, no dia da água e na semana do meio ambiente e em cadernos especiais, discutindo situações pontuais.

Muito embora os assuntos tratados impactassem na vida dos residentes dos municípios do Cabo de Santo Agostinho e de Ipojuca, não havia as "vozes" dos representantes da sociedade civil.

Entretanto, inicialmente, há o entendimento de que o discurso hegemônico da economia e do capital tem obtido a primazia, suplantado e dissimulado os impactos causados no meio ambiente pelo Complexo Industrial Portuário de Suape (CIPS), deixando evidenciada a orientação de Santos (2010) de que a informação concentrada nas mãos de pequenos núcleos empresariais pautará as discussões de forma a não comprometer seus interesses corporativos. 


\section{Referências}

ALVES, José Luiz. Suape e sua trajetória Histórica: Um Olhar Geográfico. 2011 , tese (Doutorado em Geografia). Universidade Federal de Pernambuco, Recife, 2011. $258 \mathrm{f}$.

BAKHTIN, Mikhail (Volochinov). Marxismo e filosofia da linguagem. $11^{a}$ ed. São Paulo: Hucitec, 2004.

BRASIL. Presidência da República. Secretaria de Comunicação Social. Pesquisa brasileira de mídia 2015: hábitos de consumo de mídia pela população brasileira - Brasília: Secom, 2014.

CORBETT, Julia B. Communicating Nature: how we create and understand environmental messages. Washington, DC: Island Press, 2006.

COX, Robert. Environmental Communication and the Public Sphere. $3^{\text {rd }}$ ed. Publications. London; SAGE, 2010.

CRISTO, Catarina. Governo destinará verba para acesso em Suape. Folha de Pernambuco. Caderno Economia. $1^{\circ}$ de fevereiro de 2007.

DRYZEK, John S. The politics of the earth: environmental discourses. $3^{\text {rd }}$ ed. Oxford University Press, 2013.

GARCIA, Carlos; MUSSALEM, Josué. Suape muito mais que um porto: uma visão econômica. Recife: Comunigraf, 2011.

HALL, Stuart. et al. A produção social das notícias: o mugging nos media. In: TRAQUINA, Nelson (Org). Jornalismo: questões, teorias e "estórias". Florianópolis: Insular, 2016.

LIMA, Renato. Estaleiro: obra começa em uma semana. Jornal do Commercio. Caderno de Economia, $1^{\circ}$ de fevereiro de 2007.

MARQUES FILHO, LUiz César. Capitalismo e colapso ambiental. $2^{a}$ ed. rev. e ampl. Campinas, São Paulo. Editora da Unicamp, 2016.

PERNAMBUCO deve ganhar siderúrgica de US\$150 milhões. Diário de Pernambuco. Caderno Economia. 10 de fevereiro de 2007

RIFFE, Daniel; AUST, Charles F.; LACY, Setphen R. The effectiveness of random, consecutive day and constructed week sampling in newspapaer content analysis. Disponível em: http://www.aejmc.org/ 


\section{Luciana Pereira Silva \\ Isaltina Maria de Azevedo Mello Gomes}

home/wp-content/uploads/2012/09/Journalism-Quarterly-1993-RiffeAustLacy-133-391.pdf

SANTOS, Milton. Por uma outra globalização: do pensamento único à consciência universal. 19a ed. Rio de Janeiro: Record, 2010.

THOMPSON, John B. Ideologia e cultura moderna: teoria social crítica na era dos meios de comunicação de massa. Tradução do Grupo de Estudos sobre ideologia, comunicação e representações sociais da pós-graduação o Instituto de Psicologia da PUCCS. $8^{a}$ ed. Petrópolis, RJ: Vozes, 2009.

ONU. Organização das Nações Unidas. Programa das Nações Unidas para o Desenvolvimento. Racking IDHM Municípios 2000. Disponível em: http://www.pnud.org.br/atlas/ranking/Ranking-IDHM-Municipios-2000.aspx

\section{DADOS DAS AUTORAS}

\section{Luciana Pereira Silva}

ORCID iD http://orcid.org/0000-0002-3520-4156

Universidade Federal de Pernambuco - UFPE Mestra em Ciências da Linguagem, graduada em Comunicação Social. Professora concursada para a área de Comunicação do Instituto Federal de Educação, Ciência e Tecnologia de Pernambuco - IFPE - campus Recife. Doutoranda do Programa de Pós-Graduação em Comunicação da Universidade Federal de Pernambuco - UFPE, desenvolve pesquisas com ênfase na Comunicação ambiental; mídia e meio ambiente, discurso e educação. No campo do turismo, trabalha com temas ligados ao turismo e a sociedade, turismo pedagógico e o turismo de eventos. Tem experiência profissional na área de Comunicação Governamental e Pública, Assessoria de comunicação, Gestão da comunicação.

lv06pereira@gmail.com

\section{Isaltina Maria de Azevedo Mello Gomes}

ORCID iD http://orcid.org/0000-0003-2256-8564

Universidade Federal de Pernambuco - UFPE

Professora Titular da UFPE, atua como docente no curso de Jornalismo, do Departamento de Comunicação Social da UFPE, e no Programa de Pós-Graduação em Comunicação da UFPE. isaltina@gmail.com 